\title{
Analysis of Employee's Longevity and Academic Development in Forensic Science Laboratory
}

\author{
Gloria Cuthbert Omari' ${ }^{1}$, Samwel Victor Manyele ${ }^{2}$, George Mwaluko \\ ${ }^{1}$ Department of Mechanical and Industrial Engineering, College of Engineering and Technology, University of Dar es Salaam, \\ Dar es Salaam, Tanzania \\ ${ }^{2}$ Government Chemist Laboratory Authority, Dar es Salaam, Tanzania \\ Email: gcla@gcla.go.tz,sammanyele@gmail.com
}

How to cite this paper: Omari, G.C., Manyele, S.V. and Mwaluko, G. (2019) Analysis of Employee's Longevity and Academic Development in Forensic Science Laboratory. Engineering, 11, 206-230.

https://doi.org/10.4236/eng.2019.114015

Received: May 28, 2018

Accepted: April 8, 2019

Published: April 11, 2019

Copyright $\odot 2019$ by author(s) and Scientific Research Publishing Inc. This work is licensed under the Creative Commons Attribution-NonCommercial International License (CC BY-NC 4.0). http://creativecommons.org/licenses/by-nc/4.0/

\begin{abstract}
This paper presents the detailed analysis of academic development index and longevity among forensic science laboratory (FSL) employees as the key factors for improving organizational performance based on human capital development. The data were collected from human resource database involving 171 (88\%) employees out of 195 . New mathematical formulations were developed for academic development index $A_{d}$ a measure of the time delay in academic development while working within FSL, simple longevity $\left(L_{s}\right)$ and complex longevity $\left(L_{c}\right)$, based on years served and academic certificates attained. The values of $A_{d}, L_{s}$ and $L_{c}$ were compared for different units and departments including zonal laboratories between Y2014 and Y2016. Both total and average values of $L_{s}, L_{c}$ and $A_{d}$ indicated an imbalance in the distribution of staff in different laboratories, necessitating re-allocation to improve performance. The employment trend analysis shows that the work force has been diversified from Y2004 to Y2016 leading to improved management of finance, procurement and human resource in the FSL. As a result of a training program, the percent of staff with MSc has been increasing from about 3.5\% in Y2004 to 9\% in Y2015. The average values of longevity and academic development index were observed to be the better parameters for comparing laboratories or units than the total values. Results show a balanced staff distribution based on $L_{c}$ and $A_{d}$ is inevitable for improved performance. It was concluded that the new indices $\left(A_{d}\right.$ and $\left.L_{c}\right)$ are important tools for describing the development of the workforce and competitiveness of the FSL.
\end{abstract}

\section{Keywords}

Forensic Science Laboratory, Academic Development Index, Simple Longevity, Complex Longevity 


\section{Introduction}

Staff experience and longevity in the FSL brings the competencies and ability to perform analytical work to the client's needs. Experience may be established through academic development for employees which will in turn offer professional advice for the FSL management. Academic development is a pre-requisite for promotion in some professional steps within the FSL as per government regulations for instance from senior to principal levels. Successful management of FSLs requires a great sense of self-awareness, commitment or engagement of staff and the presence of the staff in the processes. The years staff has worked stayed in the specific FSL in connection with the organization's mode of operations, creates a defined model or processes from which performance of the organization can be measured. The advantage of academic development mixed with longevity prior to promotion is that the FSL can move its technical innovations into the most inventive and profitable directions. Existing processes and employees' skills form a business model to which new technologies fit in, hence, reducing risks. To enable the technology to fit into existing processes, engaged employees with high longevity to maintain the processes, are required.

To be able to maintain the processes on daily basis, the FSL need skilled employees who perceive that their roles are of paramount importance. Well-developed staff (academically and professionally) are required which need to be created by the FSL itself by keeping them longer via effective employee development programs. This paper analyzes the staff academic development and longevity [1], by establishing new mathematical formulations and comparing results between departments and units.

All employees within FSL are eligible to academic development during their carrier, through different paths or routes depending on opportunities available to personal abilities. Academic development, staff occurrence in the FSL activities, finding a balance between effective employees and efficient laboratory service are among the driving forces for the development of the workforce. In addition, experience may be established through both academic and professional development. Figure 1 shows the possible academic development routes (A to Q) for FSL staff entering at any level.

Based on Figure 1, the FSL comprise of core cadre employees holding different certificates (diplomas, BSc, and MSc) for laboratory core cadres, to start with. The changes in the frequency distribution for each route as staff acquire different certificates with time, creates a complex dynamical system, which require detailed analysis. The letters in Figure 1 (A to Q) indicate possible routes for academic development available for FSL staff. This paper focuses on the frequency of staff following each path and assesses the relevance of each path, the time it takes for a specific staff to move from one certificate to another, and assess the relevance of each path to the FSL functions. To assist the staff aspiring to prosper academically in a useful way, a policy, funding, program and committee have been established to guide the staff and the management. Note that each 

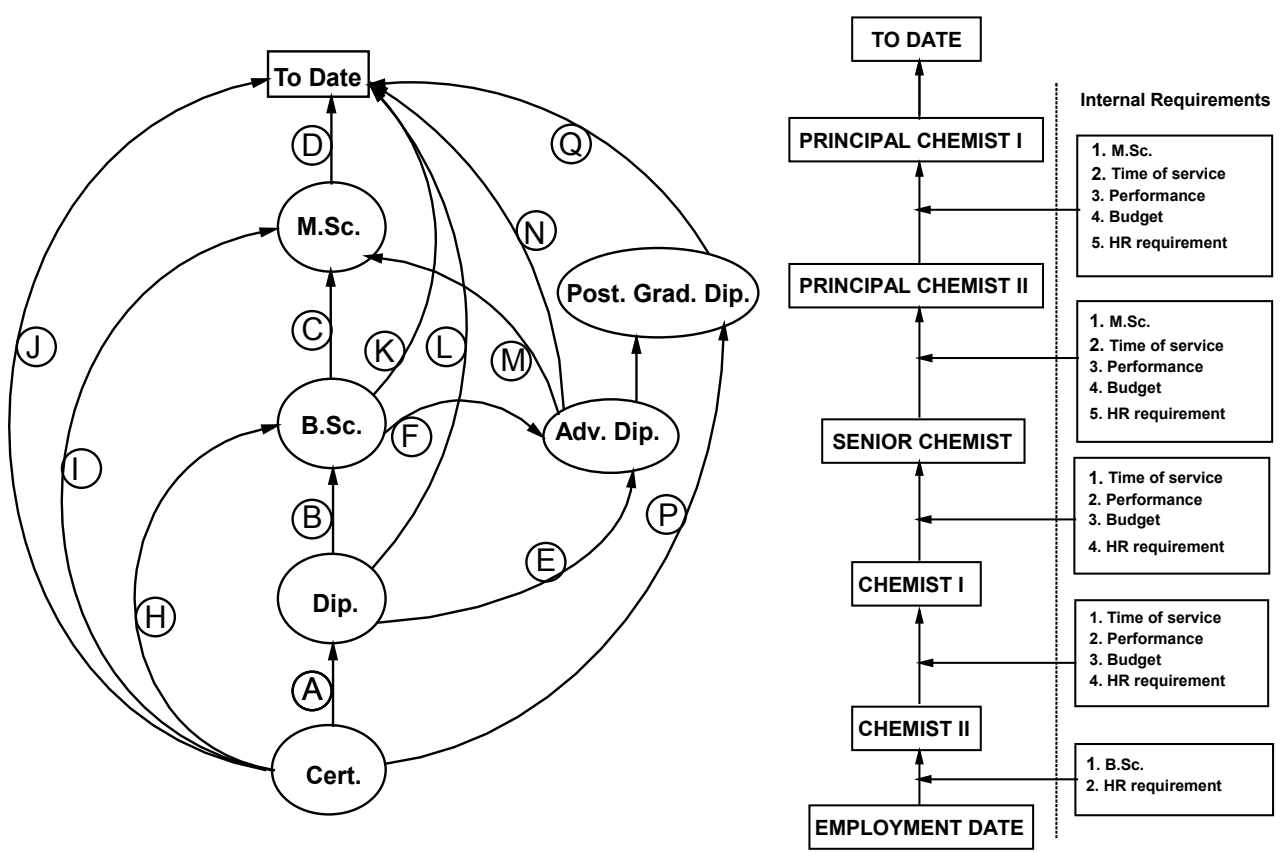

Figure 1. Academic and professional development schemes available for laboratory staff within FSL.

path ends at a box denoted as "to date", (such as A-B-C-D, H-K, H-F-N, or A-E-M-D, etc.).

Figure 1 shows also the professional development hierarchy for FSL staff (for a case of chemists) from chemists II to principal chemist. Similar charts can be made for other cadres. Starting from employment date, at any starting or entry academic level (at employment date), employees follow a professional growth path with five (by satisfying several requirements shown on the right hand side towards a top rank), that is, Principal Chemist I. It is interesting to note that MSc is one of the requirements for transition from a senior to a starting principal level. Budget for the public service and individual staff performance and readiness are critical requirements for all professional growth steps [2]. At any times, the HR manager is subjected to a state of Lc, Ad when arranging the placement of staff in laboratories

Figure 1 corresponds also to the staff's whole lifetime in the FSL from employment date to retirement, covering a period of about 40 years, maximum. Thus, Figure 1 expresses a human resource development and utilization problem in the FSL, which forms a basis of this study.

\section{Literature Review}

\subsection{The Relationship between Human Capital Development and FSL Performance}

Among the factors affecting FSL growth, development and competitiveness, is the human resource management. The human capital within the FSL has two main components which are individual staff or employees and the FSL as an organization. Human capital have four key attributes [1], that is, 1) flexibility and 
adaptability (improved via longevity and training), 2) enhancement of individual competencies (acquired through training and experience), 3) the development of the organizational competencies (including innovation, networking, facilities availability, other resources), and 4) individual employability (which may involve engagement and loyalty). Literature shows that, these attributes in turn, generate or add values to individual and organizational outcomes. There are various findings associating human capital with higher performance and sustainable competitive advantage [2] [3], higher organizational commitment [4], and enhanced organizational retention [5].

From the individual level, the importance of human capital depends on the degree to which it contributes to the creation of a competitive advantage [6]. From an economic point of view, firms gain competitive advantages when they own firm-specific resources that cannot be copied by rivals. Thus, as the uniqueness of human capital increases, firms have incentives to invest resources into its management aiming at reducing risks and capitalizing on productive potentials. Hence, individuals need to enhance their competency skills in order to be competitive in their organizations, which stresses on academic and professional development.

During human capital theory development, greater attention has been paid to training related aspects (denoted in this paper as academic development). Human capital investment is any activity which improves the quality (productivity) of the worker. Therefore, training is still an important component of human capital investment. This refers to the knowledge and training required and undergone by a person that increases own capabilities in performing activities of economic value. However, training required is that which focuses on the FSL specific activities, for which such colleges to provide training are lacking within the country and also in the region. On the other hand, research on longevity issues has not been reported compared to training and academic development.

Literature shows the importance of training on employee's productivity and firm's competitiveness, indicating that the workforce's lack of training is related to low competitiveness [7]. In turn, a greater human capital stock is associated with greater productivity and higher salaries [8]. Likewise, training is linked to the longevity of companies [9] and greater tendency to business and economic growth [10]. In addition, human capital is a source not only to motivate workers and boost up their commitment but also as expenditure in R\&D which is a difficult expense in publically owned facilities like FSL due to competing resources [6] [11]. However, investment in training is desirable from both a personal and social perspective.

Thus, FSL's human capital can add value if it contributes to lowering costs and providing increased performances. The human capital indicators such as training attended and team-work practices have a positive association with organizational performances [12] [13]. In this study, FSL employees who attended training were used as a sample in order to assess the capital investment in terms 
of training at work (academic development), delays in professional development (stagnation) and professional development challenges among staff of different professions [14]. Human capital enhancement paves a way for greater innovativeness and this in turn offers positive implications on firm performance and return of investment (ROI) of firms [15] [16] [17]. Firm performance is positively impacted by the presence of human capital practices [18] [19], while human capital development is also a prerequisite to good financial performance [2] [15] [17] [20].

\subsection{The Role of Staff Longevity on FSL Competitiveness}

Longevity is a measure of how long an employee has been working in the FSL (measured in years). This study differentiates between simple longevity (years worked in a given organization) and the newly introduced concept of complex longevity (by considering the initiatives made to improve the academic levels of the staff while building their longevity in the FSL). This paper presents the mathematical formulation for quantifying workplace complex longevity and tries to answer the question: how much of a competitive advantage is employee longevity? Employee longevity (simple and complex) is a signal of a strong company that has established some competitive advantages. Employee longevity suggests they have a lot of experience and therefore likely to be very efficient and effective. Longevity shows that the company is growing and improving over time. A growing company keeps things interesting for good employees by providing them new challenges and professional growth opportunities. Moreover, longevity suggests that the company continues to provide value to its customers and is able to raise prices or improve margins or both. A company cannot keep employees over the long-term without steady compensation increases and therefore the company needs to be creating and capturing value to be able to keep those employees.

Organizational stability stimulates longevity, because good employees stick around. High employee longevity in FSL shows that the organization has found a rhythm of work that is balanced. Employee longevity suggests that the workload (normal and the heavy bursts in FSL) is sustainable by the employees over the long term.

However, arguments against longevity exist and there are some logical reasons why longevity may not be the best tool for all organizations. For companies that need to change and adapt to new conditions, doing that with legacy staff can be difficult. Employees with experience outside the company (and who has dealt with such changes), are required to initiate major change initiatives without help of outside consultants. Having a mix of legacy and newer staff will help in moving forward, while making necessary adjustments.

\subsection{The Need for Academic Development for Laboratory Employees}

Workplace learning is conceptualized in broad and diverse ways, and essentially covers a mix of the issues pertaining to both organizations and workers [21]. It 
can refer to learning to enable work (including entry into professions and continued professional development) and, learning at work (through structured courses, training, workshops, and so on as well as "informally"). This paper focuses on academic development for staff while at work, that is, embarking on further studies during their life at FSL and attaining different certificates as shown in Figure 1.

This diversity of theories is problematic because: "[m]any researchers construct their model, conceptualization or theory of learning, with the explicit claim or by implication that it might adequately cover all aspects of workplace learning, in all contexts" [22]. This has created a potentially very confusing picture of learning associated with work. Thus, there was a need during development of this research, to clearly identify the type of learning, i.e., academic development of FSL staff. Delimiters of informal learning include problem framing capacity and intellectual ability, although informal learning can be enhanced by critical reflectivity, proactivity and creativity.

\section{Methodology}

\subsection{Study Area}

The study was conducted using GCLA as a study area, details of which are shown in Table 1. The key components included employment trends, academic

Table 1. Details of study parameters and units studied.

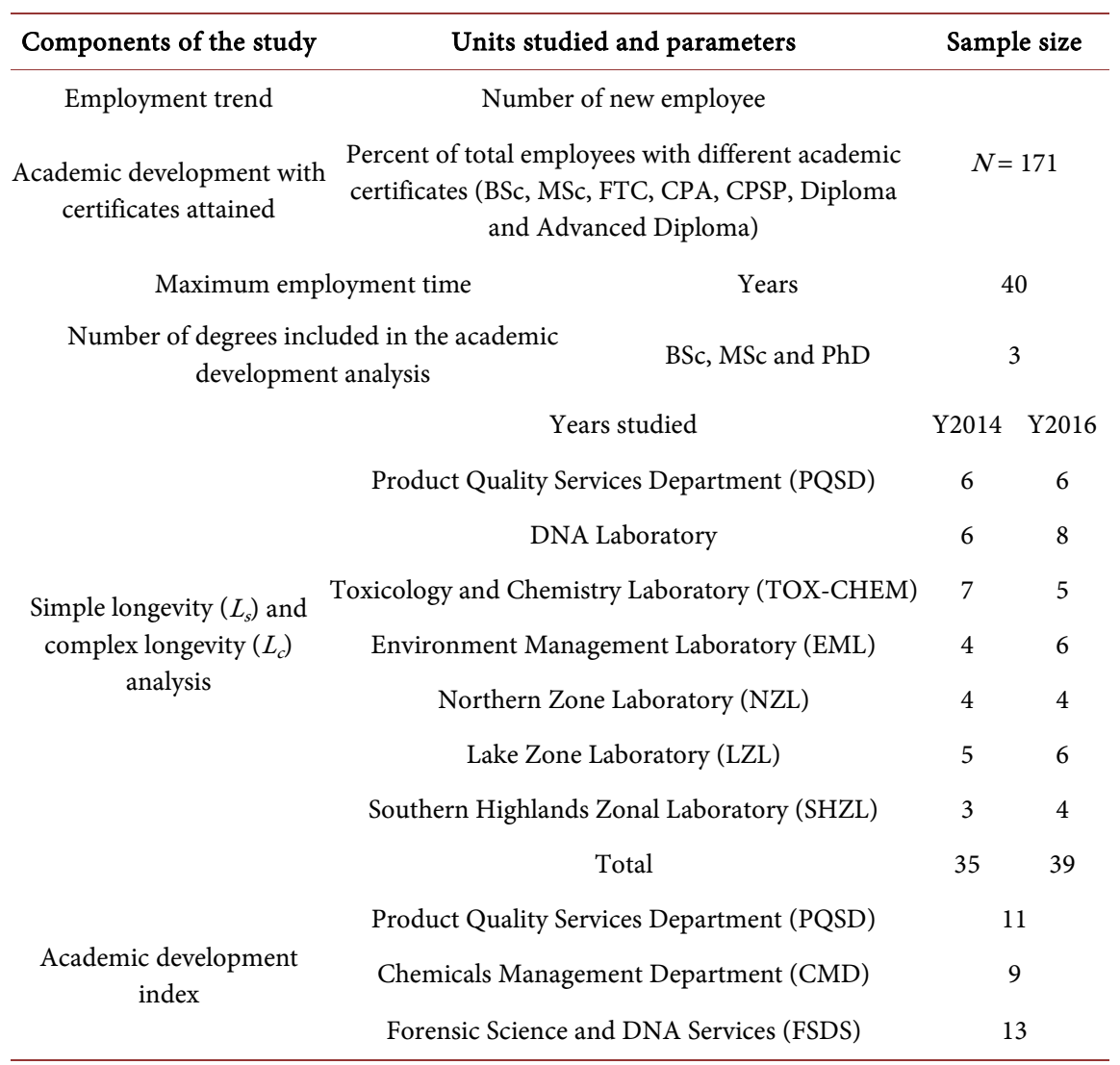


certificates, attendance in short courses and simple and complex longevity. The forensic chemistry and toxicology laboratories were combined in this analysis due to lower number of staff.

In this study, it was assumed that a strong relationship exists between longevity and academic development and that certificates attained while at work are relevant to the performance and competitiveness of the FSL. Moreover, only existing employees were considered in this analysis to assist human resource management team to decide on placement of staff in different areas. It was further assumed in this study that employees may enter the FSL at any point in time with any certificate indicated by circles or boxes in Figure 1 .

\subsection{Derivation for Simple Longevity}

This objective was accomplished through the assessment of staff experience and longevity in FSL as part of the laboratory's staff credentials or certificates which reflect broad, in-depth knowledge, sufficient expertise within the organization. Staff experience was expressed using simple and complex longevity. Simple longevity or experience, $L_{s}$, is defined as the period in years from first employment with FSL to date, given as per Equation (1):

$$
L_{s}=Y_{t d}-Y_{e}
$$

where $Y_{t d}=$ year to date, (Y2015 for this case), and $Y_{e}=$ year of first employment.

For a given laboratory, unit or zonal operations, the total staff simple longevity is determined as per Equation (2):

$$
L_{s t}=\sum_{i=1}^{N_{s}}\left(L_{s, i}\right)
$$

Let $N_{s}$ be the number of staff in a given laboratory or unit, the average simple longevity can be determined using Equation (3):

$$
\overline{L_{s}}=\frac{1}{N_{s}} \sum_{i=1}^{N_{s}}\left(L_{s, i}\right)
$$

\subsection{Derivation of Laboratory Staff Complex Longevity}

Depending on the qualification during the first employment in the FSL, that is, $\mathrm{BSc}, \mathrm{MSc}$ or $\mathrm{PhD}$, the corresponding arbitrary points, denoted as $P_{p}$ was assigned to each qualification, that is, $P_{i}=5,10$, or 20 , respectively. The values of $P_{i}$ were arbitrarily selected in that order to differentiate the weights of BSc, MSc and $\mathrm{PhD}$ certificates. Any other values could be selected in that increasing order. Each staff score, $S_{c}$ is thus defined as per Equation (4):

$$
S_{c}=P_{i} \times Y_{i}
$$

where $Y_{i}$ is equal to years the degree has been used in FSL or $L_{s}$ for the specific degree.

Given that an employee can only have a maximum simple longevity of 40 years (employed at the age of 20 years and retiring at the age of 60 years) then the maximum score is obtained when employed with $\mathrm{PhD}$ on the first day, as per 
Equation (5):

$$
\max \left(P_{i} Y_{i}\right)=P_{i}(=20) \times Y_{i}(=40)=800
$$

If at employment date in 2000 an employee had a BSc, then this BSc will have a value of $Y_{i}$ of 15 years at a reference year, Y2015 (denoted as to date). Moreover, if such an employee acquires an MSc degree in Y2010, then, the value of $Y_{i}$ for MSc will be 5 years in Y2015. All staff will have a specific score value, $P_{i} Y_{i}$ less than 800 , based on which, a normalized score for each staff can be defined as per Equation (6):

$$
N_{s c}=\frac{P_{i} Y_{i}}{\max \left(P_{i} Y_{i}\right)}=\frac{P_{i} Y_{i}}{800}
$$

The maximum of 3 certificates for each staff were considered in this study, that is, at BSc, MSc, and PhD levels, defined as $j=1,2,3$. The total normalized score, $N_{\text {sct }}$ is defined as complex longevity for each staff, given as per Equation (7):

$$
L_{c k}=N_{s c t}=L_{j}=\sum_{j=1}^{3}\left(\frac{P_{i} Y_{i}}{800}\right)
$$

For each value of $j$, a different degree is considered, and the time since it was received is multiplied by the degree score, $P_{i}$. Each staff will be represented by a single value of $N_{s c t}$ or $L_{c}$ which is the measure of how useful the academic qualification of the specific staff has been in the FSL, and also indicates a measure of staff experience. The quantity, $L_{\mathcal{c}}$ is thus a compound measure taking care of both time elapsed since a given degree was obtained and academic credentials possessed thereafter. For comparison between different laboratories or FSL units, the total values of $L_{c}$ for all staff in the laboratory can be used. Assuming that a laboratory has $N_{s}$ staff members, then the staff members will vary as $k=1$, $2,3, \ldots, N_{s}$, then total complex longevity for that laboratory will be determined as per Equation (8):

$$
L_{c t=} \sum_{k=1}^{N_{s}}\left[\sum_{j=1}^{3}\left(\frac{P_{i} Y_{i}}{800}\right)\right]
$$

For a laboratory or unit with Ns staff, the average complex longevity can be determined as per Equation (9):

$$
\overline{L_{c}}=\frac{1}{N_{s}} \sum_{k=1}^{N_{s}}\left(L_{c, k}\right)
$$

Table 2 shows the sample calculations for $L_{c}$ and $L_{c t}$ for laboratory staff based on Equations (1) to (9).

Higher value of $L_{c}$ implies that a specific employee has worked in the laboratory for many years with those years supported by degrees or certificates obtained while working in the FSL.

\subsection{Determination of Academic Development Index}

Another measure of staff experience was established through academic development index where courses relevant to the job requirements are taken. Academic 
Table 2. Sample calculations for values of $L_{c}$ and $L_{c t}$ by Y2016.

\begin{tabular}{|c|c|c|c|c|c|c|c|c|}
\hline \multirow{2}{*}{ Staff identifier } & \multicolumn{2}{|c|}{ Simple Longevity } & \multirow{2}{*}{\multicolumn{2}{|c|}{$\begin{array}{l}\text { Qualification and } \\
\text { year attained }\end{array}$}} & \multirow{3}{*}{$\begin{array}{c}\text { Points }=P_{i} \\
5\end{array}$} & \multirow{3}{*}{$\begin{array}{c}\text { Years to } \\
\text { date }=Y_{i}\end{array}$} & \multirow{3}{*}{$\begin{array}{l}\text { Score } \\
0.1563\end{array}$} & \multirow{3}{*}{$L_{c, i}$} \\
\hline & \multirow[t]{2}{*}{$Y_{e}$} & \multirow[t]{2}{*}{$L_{s}$} & & & & & & \\
\hline & & & BSc & 1991 & & & & \\
\hline \multirow[t]{3}{*}{ A } & 1991 & 25 & MSc & 2004 & 10 & 12 & 0.1500 & 0.3063 \\
\hline & & & $\mathrm{PhD}$ & - & 20 & 0 & 0.0000 & \\
\hline & & & $\mathrm{BSc}$ & 1995 & 5 & 21 & 0.1313 & \\
\hline \multirow[t]{3}{*}{ B } & 1995 & 21 & MSc & 2012 & 10 & 4 & 0.0500 & 0.1813 \\
\hline & & & $\mathrm{PhD}$ & - & 20 & 0 & 0.0000 & \\
\hline & & & $\mathrm{BSc}$ & 2008 & 5 & 8 & 0.0500 & \\
\hline \multirow[t]{3}{*}{ C } & 2008 & 8 & MSc & - & 10 & 0 & 0.0000 & 0.0500 \\
\hline & & & $\mathrm{PhD}$ & - & 20 & 0 & 0.0000 & \\
\hline & & & $\mathrm{BSc}$ & 2010 & 5 & 6 & 0.0375 & \\
\hline \multirow[t]{3}{*}{$\mathrm{D}$} & 2010 & 6 & MSc & - & 10 & 0 & 0.0000 & 0.0375 \\
\hline & & & $\mathrm{PhD}$ & - & 20 & 0 & 0.0000 & \\
\hline & & & $\mathrm{BSc}$ & 2005 & 5 & 11 & 0.0688 & \\
\hline \multirow[t]{2}{*}{$\mathrm{E}$} & 2005 & 11 & MSc & 2011 & 10 & 5 & 0.0625 & 0.1313 \\
\hline & & & $\mathrm{PhD}$ & - & 20 & 0 & 0.0000 & \\
\hline \multicolumn{2}{|c|}{ Total simple longevity, $L_{s t}$} & 71.00 & \multicolumn{4}{|c|}{ Total complex longevity, $L_{c t}$} & & 0.7063 \\
\hline \multicolumn{2}{|c|}{ Average simple longevity, $\overline{L_{s}}$} & 14.2 & \multicolumn{4}{|c|}{ Average complex longevity, $\overline{L_{c}}$} & & 0.1413 \\
\hline
\end{tabular}

development is a factor of skills gained during the studies, as well as a demonstration of effective ways to study and manage time. Given the year of employment, $Y_{e}$, with a starting qualification (Certificate, Advanced Diploma, BSc, MSc or $\mathrm{PhD}$ ), any added degree or certificate, $Y_{t}$ years later, adds to staff academic development. The academic development index, denoted as $A_{\phi}$ quantifies the delay time for a specific staff from one degree or certificate to another, determined as per Equation (10):

$$
A_{d}=1+\left[\sum_{i=1}^{n}\left(\frac{1}{Y_{t}}\right)\right]+\frac{1}{L_{s f d}}
$$

where $Y_{t}=$ years from the first graduation, to the next graduation, while working within the FSL, and $L_{s f d}=$ simple longevity of last degree or certificate in years, and $n=$ number of degrees or certificates. The base value of $A_{d}=1$, corresponds to the value of $A_{d}$ for the certificate leading to employment in the FSL and $n$ is the number of degrees or certificates attained. When $L_{s f d}=L_{s}$, a condition satisfied when an employee did not attain any other degree or certificate from first employment, then adding $1 / L_{s}$ to $A_{d}$ signifies that an employee who had worked longer in the laboratory should have made efforts in attaining a next certificate, provided that the last certificate was not a $\mathrm{PhD}$. A measure of delay is given by the reciprocal of $L_{s f d}$ or $L_{s}$. Higher value of $A_{d}$ signifies that a given staff has 
gained additional certificates faster or in short time intervals, while working within the FSL. For a laboratory with $N_{s}$ staff, the average academic development index was determined as per Equation (11):

$$
\overline{A_{d}}=\frac{1}{N_{s}} \sum_{i=1}^{N_{s}} A_{d, i}
$$

Higher values of $A_{d}$ signify staff who acquired the degrees in short time intervals (shorter $Y_{t}$ and hence high reciprocal values). Lower value of $A_{d}$ indicates that the corresponding staff attained the degree after a longer time interval (high $Y_{t}$ and hence lower reciprocal values) or none of certificates were attained after employment (routes J, K, L, N, Q, D in Figure 1). Figure 3 shows the conceptual model used for determination of academic development index. Table 3 shows sample calculations for $A_{d}$ from a sample laboratory with 6 staff members. After computing the $A_{d}$ for each employee in FSL, comparison of staff academic development index will be used for comparing the different laboratories or units.

\section{Results and Discussion}

\subsection{Employment Trend for Laboratory Core Cadres}

Figure 2 shows the time variations of percentage staff with FTC, BSc, and MSc (out of $N=171$ employees) from the Y2000 to Y2015. This comprise of laboratory carders which can perform analysis and maintain laboratory equipment and facilities. The percentage of employees with BSc rose starting from $3 \%$ to $18 \%$ between Y2004 and Y2015, respectively, being the highest throughout the study period. The number and hence the fraction of employees with MSc increased in the same period from about 3.8\% in Y2014 to 9\% in Y2015 due to increased training opportunities for MSc. This increase of employees with science degrees is a result of human resource planning during employment and internal FSL carrier development program for employees and their personal efforts by staff embarking into MSc programs with most of such carrier development sponsored by the FSL led to improved number of MSc holders.

Table 3. Sample calculation of $A_{d}$ values by 2015 .

\begin{tabular}{|c|c|c|c|c|c|c|c|c|c|c|c|c|c|c|c|c|c|c|c|c|c|}
\hline \multirow[b]{2}{*}{$\mathrm{S} / \mathrm{N}$} & \multicolumn{2}{|c|}{ Staff details } & \multicolumn{6}{|c|}{ Year attained } & \multicolumn{6}{|c|}{$Y_{t}$} & \multicolumn{6}{|c|}{$1 / Y_{t}$} & \multirow[b]{2}{*}{$\sum\left(\frac{1}{Y_{t}}\right)$} \\
\hline & $\mathrm{Y}_{\mathrm{e}}$ & 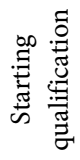 & 岗 & $\begin{array}{l}\dot{A} \\
\dot{\theta} \\
\dot{\vec{\theta}}\end{array}$ & $\sum_{\check{\Sigma}}^{\breve{n}}$ & 荀 & $\begin{array}{l}\mathscr{\Xi} \\
\stackrel{0}{0} \\
\stackrel{0}{\circ} \\
\stackrel{0}{0}\end{array}$ & 咅 & $Y_{t 1}$ & $Y_{12}$ & $Y_{t 3}$ & $Y_{t 4}$ & $Y_{t 5}$ & $L_{s f d}$ & $\frac{1}{Y_{t 1}}$ & $\frac{1}{Y_{t 2}}$ & $\frac{1}{Y_{t 3}}$ & $\frac{1}{Y_{t 4}}$ & $\frac{1}{Y_{t 5}}$ & $\frac{1}{L_{s f d}}$ & \\
\hline A & 1995 & $\mathrm{MSc}$ & - & - & 1995 & - & - & - & - & - & 1 & - & - & 20 & - & - & 1 & - & - & 0.05 & 1.050 \\
\hline B & 2005 & $\mathrm{BSc}$ & 2005 & - & - & 2011 & - & - & 1 & - & - & 6 & - & 4 & 1 & - & - & 0.167 & - & 0.25 & 1.417 \\
\hline C & 1982 & Dip & - & - & - & - & 1982 & - & - & - & - & - & 1 & 33 & - & - & - & - & 1 & 0.03 & 1.030 \\
\hline $\mathrm{D}$ & 2005 & $\mathrm{BSc}$ & 2005 & - & 2010 & - & - & - & 1 & - & 5 & - & - & 5 & 1 & - & 0.2 & - & - & 0.2 & 1.400 \\
\hline E & 1986 & $\mathrm{BSc}$ & 1986 & - & 1995 & - & - & - & 1 & - & - & 9 & - & 20 & 1 & - & - & 0.111 & - & 0.05 & 1.161 \\
\hline F & 2008 & $\mathrm{BSc}$ & 2008 & - & - & - & - & - & 1 & - & - & - & - & 7 & 1 & - & - & - & - & 0.143 & 1.143 \\
\hline
\end{tabular}




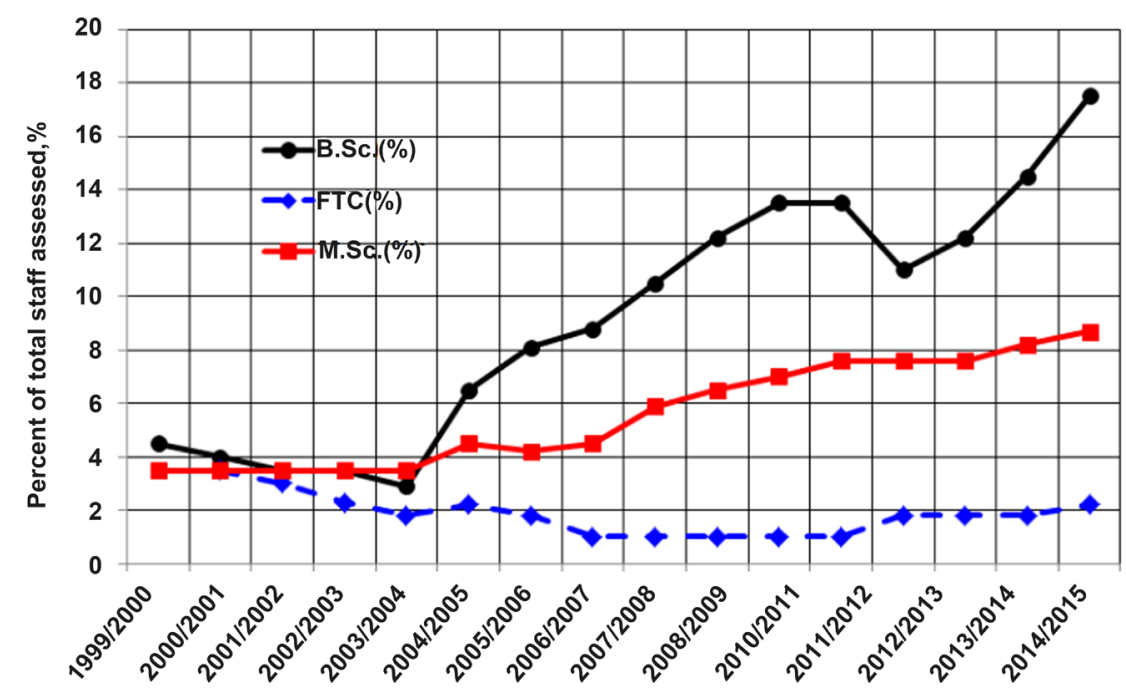

Figure 2. Employee mix time series for laboratory core carders.

The decrease in BSc percentage from 5\% to 3\% between Y2000 and Y2004, respectively, can be attributed to the need for business competitiveness which necessitated introduction of additional skills or professions and disciplines such as certificates, to complement the core carder for new functions such as accounting and procurement management which slightly diluted the BSc. Chemists with BSc have been given great opportunities and support to acquire MSc in order to improve the FSL analysis capability but also as a carrier or professional development requirement from a senior chemist level to a principal chemist (as per Figure 1). This is depicted by the increase in percentage of staff with MSc, shown in Figure 2.

Figure 3 shows the trends in percentage of different certificate holders in the FSL laboratory carders for the three consecutive five-year terms from 1999 to 2015. While the percentage of BSc increased from $26.7 \%$ to $37 \%$ in 15 years, MSc fraction dropped slightly from $23.6 \%$ to $22.5 \%$. The percentage of FTC holders has been decreasing from $17.4 \%$ before 2005 to $7.9 \%$ by 2015 . While the actual number of BSc holders has been on a rise from 2005 to 2010 and also from 2010 to 2015 , the percentage increase observed was small, attributable to the similar increase in the number of degrees or certificates from social sciences, that is, diploma and certificate holders for support cadres.

Figure 4 shows the overall distribution of the academic levels from Y2000 to Y2015, together with a snapshot of the distribution for the Y2015 for BSc, FTC, and MSc. It is interesting to note that BSc and MSc comprise of largest parts of $28.6 \%$ and $14.3 \%$, respectively, on an overall basis. The functional requirements for BSc and MSc are complemented by FTC holders and in some cases by diploma holders (laboratory assistant), keeping the FSL at its competitive edge. The snapshot for the year 2015 alone shows that the core laboratory cadre comprise of $46.7 \%$ of the whole workforce, which is still low. The proportion of MSc at $31 \%$ of the laboratory cadre is encouraging as it indicates higher leadership and succession potential within the FSL [23]. 


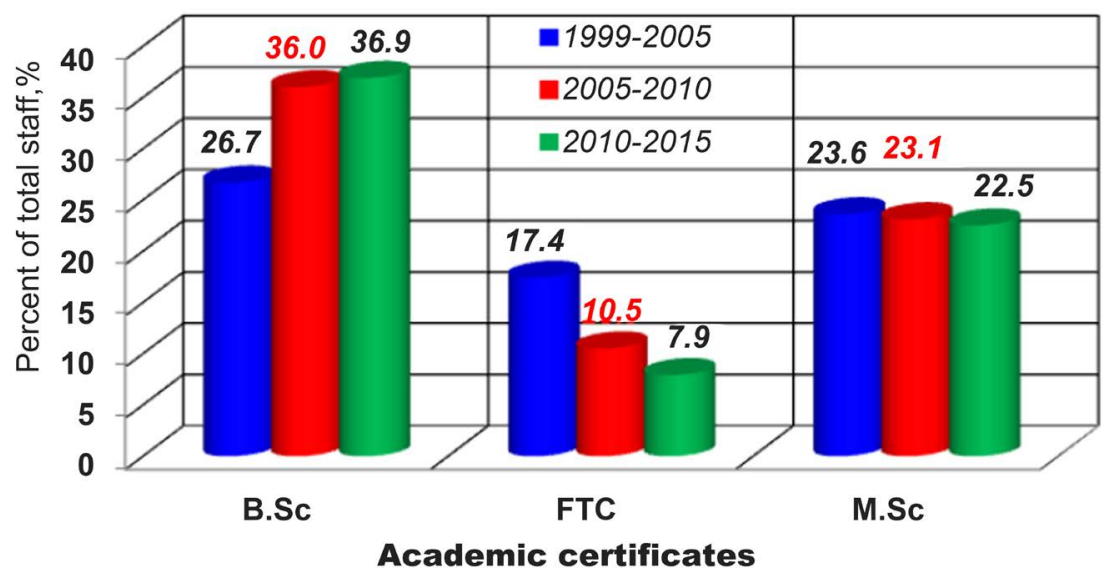

Figure 3. Comparison of the staff academic certificates mix for the core cadres in the FSL in three different 5 -year periods.

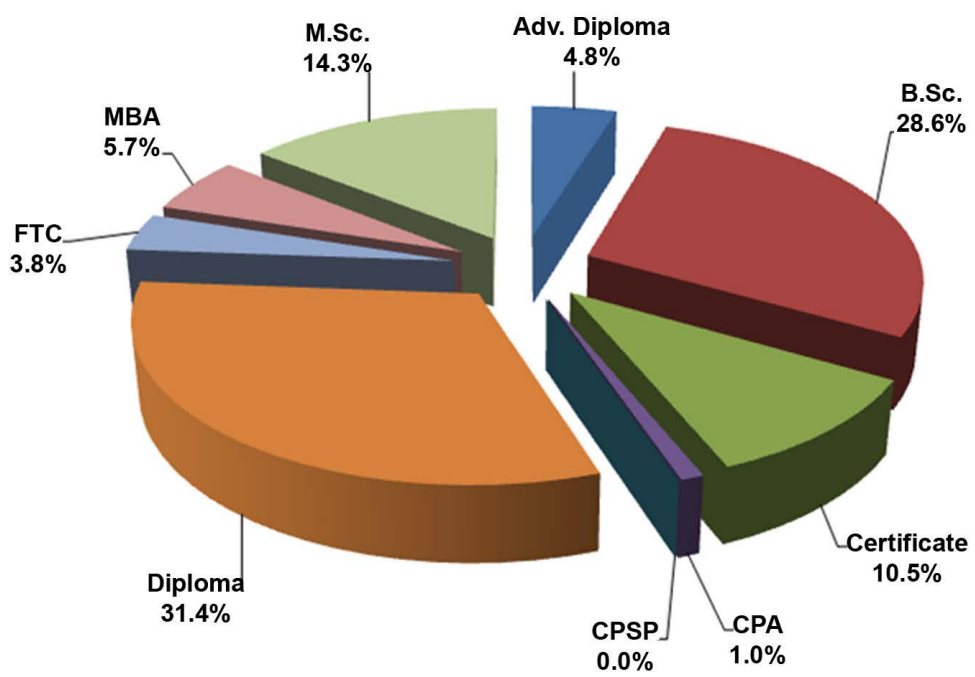

(a)

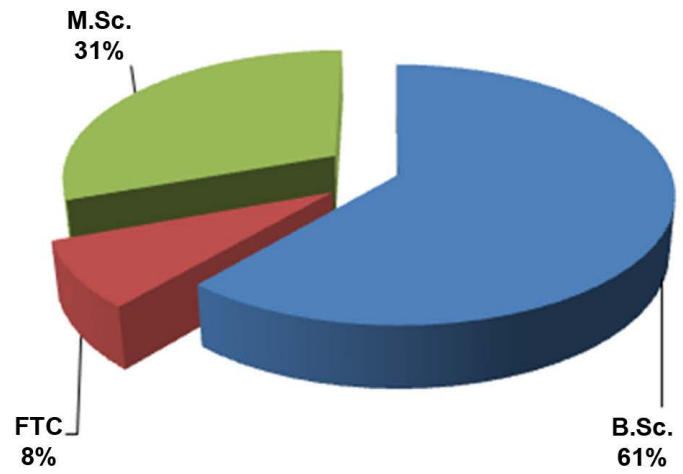

(b)

Figure 4. Current distribution of the academic certificates for the FSL and for core cadres. (a) Overall distribution for all cadres in 2015; (b) Distribution for core cadres in 2015.

Figure 4 shows also that there is an increase in the number of diploma holders compared to the past, mainly due to the need for improvements in laboratory attendants' duties, accounts and financial management, and library services to 
monitor sensitive documentation for confidentiality and staff records management. In the past, such cadres were inexistence, leading to staff complaints in the records, remunerations, and pension funds management. However, the number of diploma holders need to be minimized while increasing the scientific workforce for the competitiveness improvement of the FSL, especially in delivery of its core functionalities.

\subsection{Academic Certificates Mix for Support Cadres' in the FSL}

Figure 5 shows the time series of percentage of support carders with different certificates from Y2000 to Y2015. The fraction of staff with diplomas also increased from Y2004 to 2015, reaching a maximum of about 20\%. This can be attributed to the increased demand for secretarial services, assistant accountants, librarians, laboratory attendants, and registry. With exception of certificate holders, most of the academic certificates for support cadres are emerging or new to the FSL portfolio. For example, CPAs emerged in 2009, advanced diploma in Y2008, MBA in Y2008, while CPSP certificates were first presented in 2011. Up to Y2004, the support cadre comprised workforce with diplomas and certificate holders only, while between Y2004 and Y2008, advanced diplomas were added to the workforce portfolio. Such an emerging carrier growth development for support carders is necessary for keeping the competitive edge of the FSL.

Results in Figure 5 show the diversification of workforce from Y2004 onwards from financial management and procurement management to human resource management a move supported by researchers in human resource management [23] [24]. Thus, academic skills expansion was an inevitable move for FSL. Most of employees took evening studies to sharpen their carriers, but also to attain promotions. Investment in training has improved the FSL's financial standing. Moreover, attending customer needs require academic and professional competence. The FSL employees are currently capable of re-orienting in different

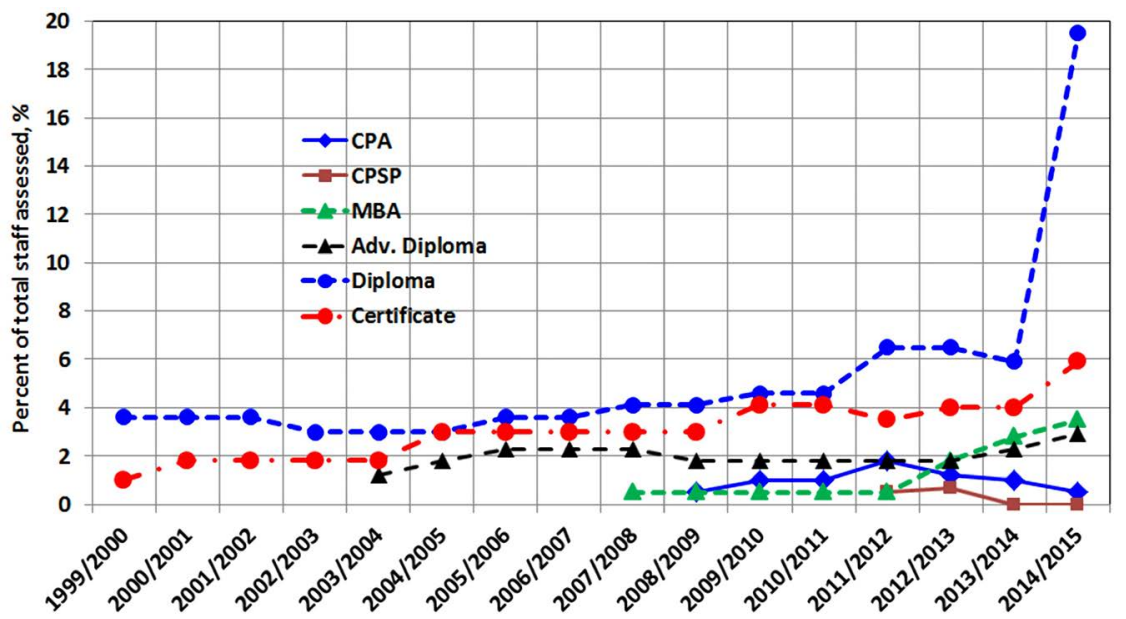

Figure 5. Time series of the percent of staff certificate holders for support cadres in the FSL. 
ways of working depending on situation. Training can help solve these performance problems by explaining the details of the job aiming at reducing duplication of effort in the workplace. The time spent correcting mistakes and the problem solving necessary to correct poor performances is reduced by training. Improved performance from employee training and diversification can reduce staff turnover, lower maintenance costs by reducing unnecessary equipment breakdowns and result in fewer customer complaints. Better performance from employees typically creates less need for supervision and brings increase work output.

\subsection{Analysis of Staff Longevity in the FSL}

\subsubsection{Simple Longevity for Individual Staff in Different Laboratories}

Keeping well-trained employees longer in an organization pays off significantly for companies because the cost of employee turnover is always high. Such costs include exit interviews, administrative functions related to termination, severance pay and unemployment compensation where applicable. Replacement costs consist of attracting applicants, entrance interviews, travel and moving expenses, pre-employment administrative expenses, medical exams and employment information. Thus, having employees with high longevity is an achievement and advantageous to the organization. This study analyzes simple and complex longevity for the FSL employees up to Y2016. Figure 6 shows the values of individual staff simple longevity for laboratory staff from different FSL units. The number of dots shows the number of laboratory scientists in the respective unit, with SHZ having the least number.

While some employees have worked up to 31 years in the EML, some of the staff had lowest simple longevity of 1 year. Such a mix allows the newly employed staff ( $L_{s}<5$ years) to learn from those with high longevity in the laboratory $\left(L_{\mathrm{s}}>25\right)$. The benefits of having units with highest and lowest $L_{\mathrm{s}}$ values was also reported in terms of succession index and leadership competency index [23].

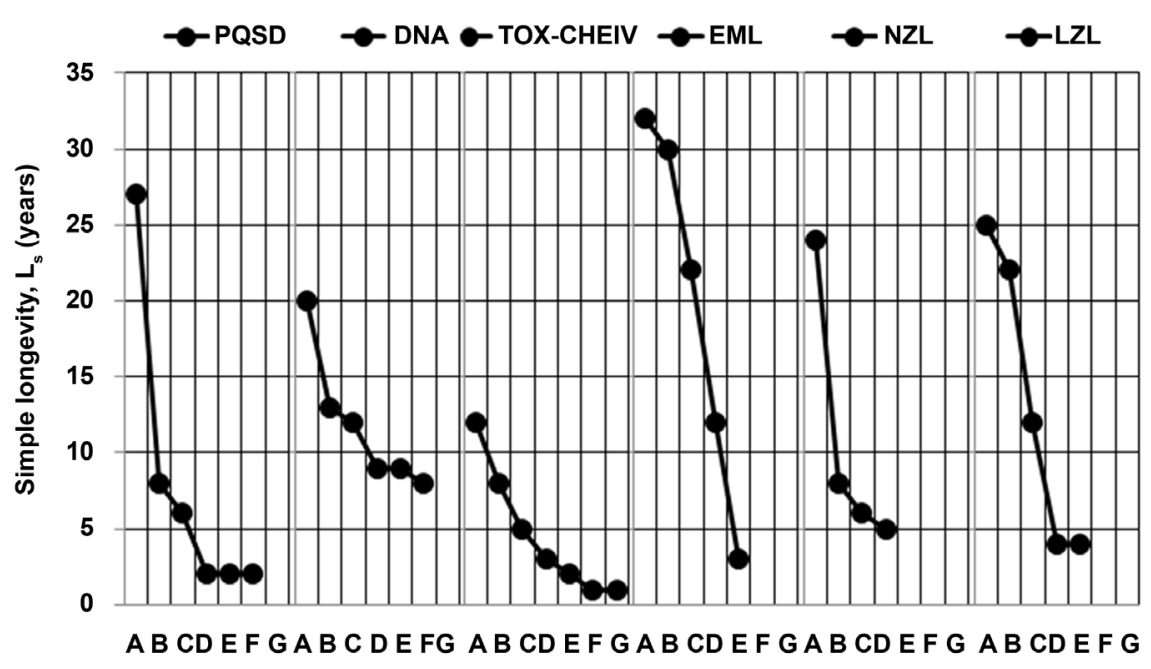

Figure 6. Comparison of the individual staff simple longevity in different FSL units. 
Figure 6 shows that some laboratory settings have high minimum simple longevity, $L_{\mathrm{s}} \geq 5$ years (DNA, EML and LZL) at a time the $L_{s}$ values were determined (that is, Y2016), while other laboratories like PQSD and TOX-CHEM had lowest minimum values of the $L_{s}<5$ years.

Analyzing values of $L_{s}$ per individual staff do not provide a measure of whole laboratory strength in tackling challenges in laboratory work. The combined staff experience was established using total staff longevity in a given laboratory, $L_{s t}$, which was further used to compare different laboratories as shown in Figure 7. For comparison of laboratories or units in terms of staff longevity, total values of $L_{s}$ were also used, as per Equation (3). Figure 7 compares total staff simple longevity values (in years) determined in Y2014 and two years later in Y2016 for core cadres in different FSL units at the headquarters and zonal laboratories. For each staff, $L_{s}$ values were calculated from date of employment (as reference) to the year Y2014 and Y2016, respectively. The values of total longevity vary for different laboratories depending on number of staff and actual years since employment for each individual staff. Thus, newly employed staff will contribute less to the total simple longevity of the laboratory and vice versa, but will benefit by learning when they work with staff with high values of individual simple longevity. This concept is useful in deciding placement of staff in laboratories and units in order to arrive at a balance in staff experience which is a requirement for efficient accomplishment of tasks. However, DNA analysts for example can be easily moved to other laboratories to balance the workforce, but a deficiency in this laboratory cannot be filled by placing staff from other laboratories due to the specialty knowledge and experience required.

Figure 7 shows also that PQSD, EML and LZL had highest values of total simple longevity in both Y2014 and Y2016. Lowest values of $L_{s t}$ were observed in TOX and CHEM for Y2016 and SHL for both Y2014 and Y2016. Thus, the data gives a guide to the decision makers when required to re-allocate staff such that the values of $L_{s t}$ are comparable for all laboratories, hence allowing for equal capacity in problem solving, innovation, supervision and hence competitiveness of the FSL as a whole. However, such a re-allocation should be done while considering other costs such as transfer and administrative posts held by the staff

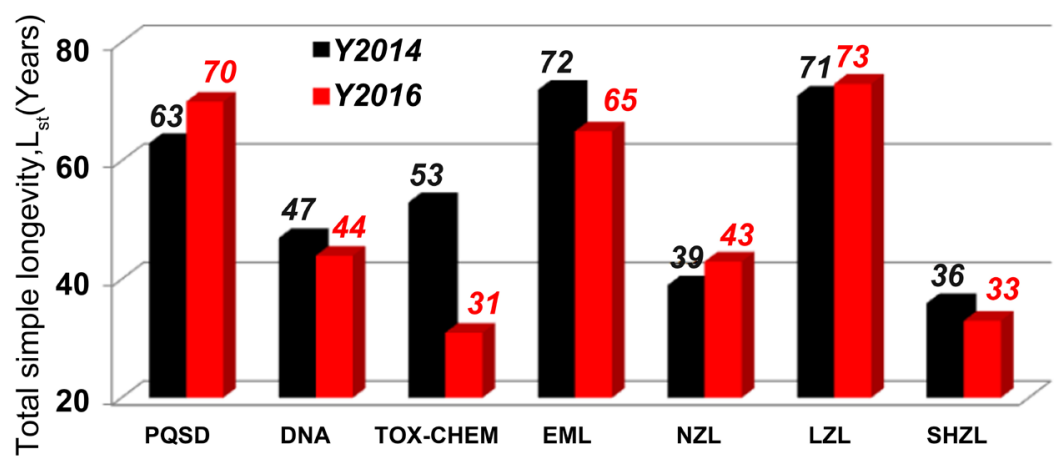

Figure 7. Values of total staff simple longevity, $L_{s \mathfrak{r}}$ for different FSL units (for Y2014 and Y206). 
within FSL. The changes in $L_{s t}$ for different units are caused by staff movement from one unit to another, retirement and movement in and out of the FSL.

Figure 8 compares the average simple longevity values for staff in different laboratories between Y2014 and Y2016. The lowest average value of 4.4 years was observed in the TOX-CHEM for the year Y2016, while the maximum value of 16.3 years was observed in EML in the same year. Results show that LZL and EML still exhibited higher average values compared to other laboratories. The DNA laboratory shows lower values indicating that the team comprises of mainly recently employed staff. This is attributable to enactment of the new law (Human DNA Regulation Act, 2009), which led to the expansion of biology laboratory into DNA testing facility, and also due to increased demand for forensic and paternity analysis. With exception of the DNA laboratory, staff in other laboratories (PQSD, EML, TOX-CHEM) can be re-allocated to give a balance in terms of staff experience and longevity. However, such re-allocation is limited for transfers to and from the zonal laboratories for which staff movement has greater financial implications. Results in Figure 8 show also that the zonal laboratories are already in balance state with average simple longevity ranging between 10.8 and 14.6 years for the year Y2016.

\subsubsection{Individual Staff Complex Longevity in Different Laboratories}

Figure 9 shows the individual staff complex longevity, $L_{\mathcal{C}}$ for laboratory core carders from different units and zonal laboratories. The values of $L_{c}$ ranged from a minimum of 0.00625 (equivalent to $P_{i}=5$ and $Y_{i}=1$ ) to a maximum of 0.45 (observed at NZL, as shown in Figure 9). However, the maximum possible value of $L_{c}$ is 1.0, for a staff employed with FSL with PhD at the first day at an age of 20 years leading to $L_{s}=40$ years (which sets the maximum possible score of 800). Again, highest values of $L_{c}$ were observed for EML and NZL $\left(L_{c}>0.4\right)$. Compared to Figure 7 for PQSD, $L_{s t}$ values were among the highest about 70 years in Y2016, while the $L_{c t}$ values are also lowest indicating that staff did not engage in higher degrees during the studied period. Thus $L_{c}$ data can be used for decision making during appointing staff for further studies. This is normally taken into consideration by setting the minimum service time before an employee can be allowed to engage into further studies, that is, 3 years.

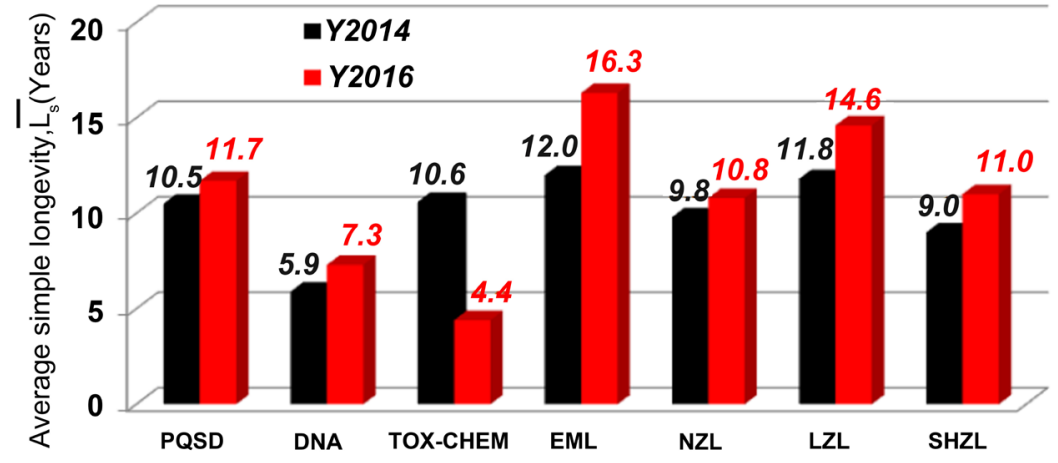

Figure 8. Values of average simple longevity for different FSL units (for Y2014 and 206). 


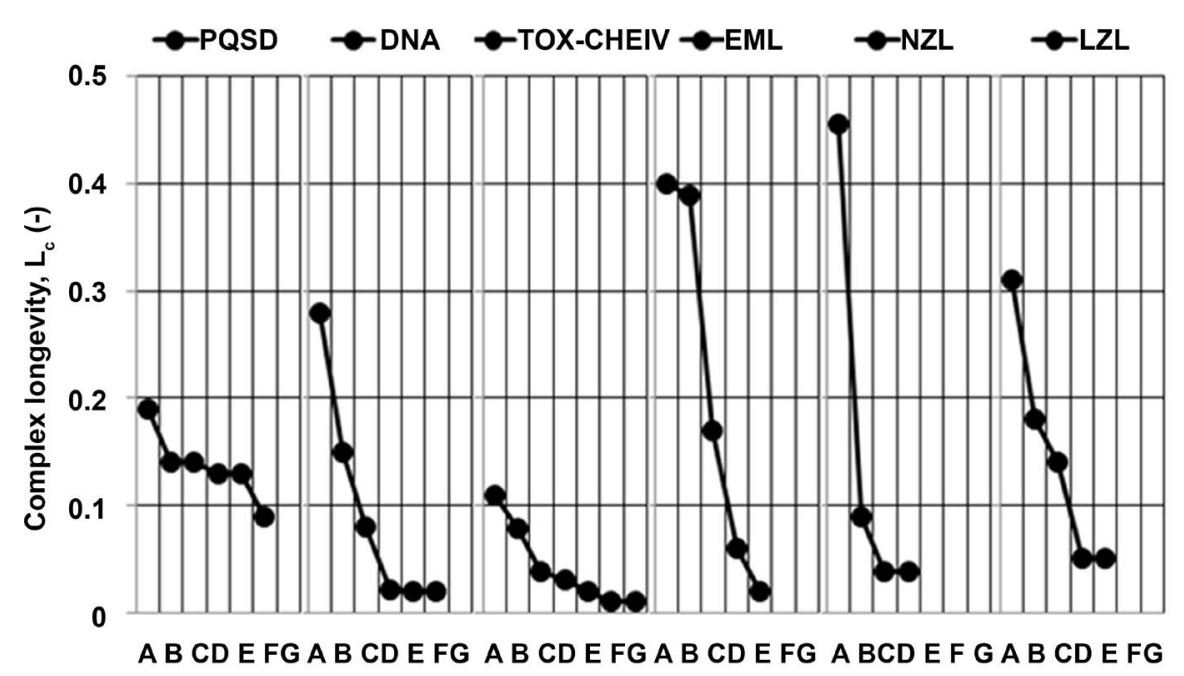

Figure 9. Values of individual staff complex longevity for Laboratory carders from different settings (units and zonal laboratories for Y2016).

Laboratory units comprising staff with high complex longevity values will have advantage in problem solving, innovation, leadership and skills in equipment and facility management. Moreover, such individuals are familiar with policies and regulations, related to forensic science services. Thus based on results presented in Figure 9, $L_{c}$ values above 0.3 correspond to staff expected to have good leadership skills due to long term experience within FSL but also due to high academic qualifications, such laboratories will also have high leadership competency index and high succession index. The lowest maximum values of $L_{c}$ were observed for forensic toxicology and chemistry combined (TOX-CHEM) indicating that new staff with mainly BSc occupied the two laboratories.

Figure 10 presents the PDF of complex longevity values for FSL staff in Y2014 and Y2016. The overall mean value of complex longevity increased from 0.1074 to 0.1254 , as expected, since more staff gained new certificates with time. The PDFs have similar shape with highest frequency at lower $L_{c}$ value of about 0.02 . For $L_{c}>0.1$, the PDFs depict multi-modal behavior with several peaks. The PDFs are also highly skewed to the right, with similar range of skewness values, i.e., 10.4 and 10.3 for Y2014 and Y2016, respectively.

\subsubsection{Analysis of Total and Average Complex Longevity}

Figure 11 shows the values of total complex longevity, $L_{c b}$ for different laboratories and zonal laboratories which were further compared between Y2014 and Y2016. Forensic chemistry and toxicology laboratories were observed to have lowest values of $L_{c t}$ indicating that the laboratory comprised of recently employed staff without advanced degrees. Between Y2014 and Y2016, some of the laboratories dropped while others increased in terms of total staff complex longevity, $L_{c t}$ This is mainly caused by staff movement from one unit to another, from headquarters to zonal laboratories, and vice versa, a situation which is inevitable. In between Y2014 and Y2016, the PQSD and NZL increased $L_{c t}$ from 


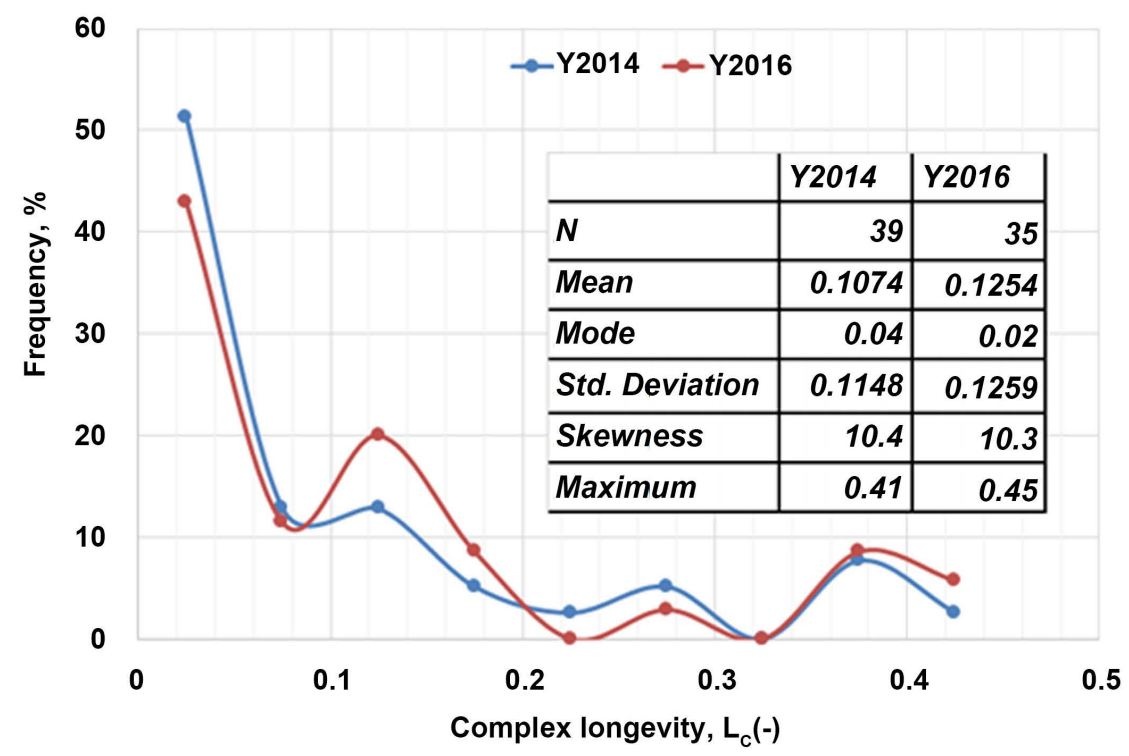

Figure 10. PDF of complex longevity data for the sample FSL employees.

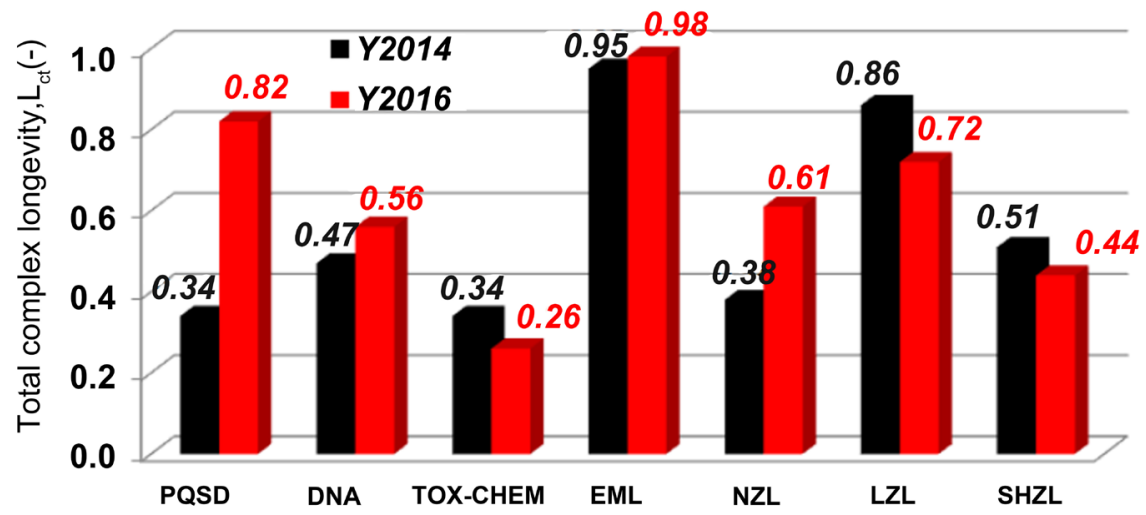

Figure 11. Comparison of total staff complex longevity for different laboratories.

0.34 to 0.82 and 0.38 to 0.61 , respectively. For the LZL, $L_{c t}$ dropped from 0.86 to 0.72 due to movement of analysts with MSc for undertaking administrative duties in laboratories at the headquarters. Highest values of $L_{c t}$ were observed for EML and LZL, indicating that highly experienced staff or large number of staff occupy these laboratories.

The total complex longevity, on the other hand, signifies the strength of a team culture rather than a "star" culture. Star culture often tolerates star performers that can be difficult to work with and may make an organization more difficult for everyone else. The stars are also not likely to stick around very long as they will be off to the next place that makes them feel like more of a star. Moreover, higher staff complex longevity shown in Figure 10 suggest strong and healthy organization team culture because a poor company team culture cannot retain employees for too long. The total complex longevity can be misleading as it can be higher just because of the large number of employees with lower individual complex longevity. Thus, it is important to make use of extra indicator 
like the average $L_{c}$ value for each unit, which expresses the laboratory performance in more statistical combination as shown in Figure 12.

Figure 12 shows a balanced state for average complex longevity in the zonal laboratories, as reported also in Figure 8, especially in Y2016. The problem of imbalanced average $L_{c}$ for EML, TOX-CHEM and PQSD depicted also in Figure 12 requires re-allocation of staff to attain an equal distribution of the staff and build FSL competitiveness, establish and sustain good customer care, improve problem solving capacity and motivation in the laboratory work. The values of average $L_{c}$ were lowest for TOX-CHEM, which decreased from 0.068 to 0.037 between Y2014 and Y2016 necessitating action by the management.

In many ways, employee complex longevity adds value to a company's competitive advantage. In cases where employee's longevity has negative impacts to the firm competitiveness, the businesses in such industries or companies are more likely to have management-labor strife. This is because the dynamics of such industry are more about capturing a larger slice of the pie rather than trying to work together to make the pie larger (a competitive distributive approach vs. a cooperative integrative approach to business). If the company needs employee wages to be low in order to survive, the company may want a constant influx of entry-level employees so that the higher paid employees move on after a few years. Lower longevity is also needed by some firms when companies need a constant source of fresh thinking. Moreover, some types of work may be difficult to do for a long period, such as physically demanding work.

There are several advantages of high longevity in the FSL. First, new hires get to know the organization, the history, the way of doing business, generally referred to as the "culture" from those with high longevity or supervisors. However, new employees don't learn FSL stuff overnight or even in two years. While there are some serious savings from reducing turnover and keeping people on long-term, there are also serious repercussions to keeping the wrong people for a long time.

In today's hiring environment, the economic situation has been altered by huge pool of experienced, but older candidates. For those looking for employees who will bring a loyal and long view of employment, these hires are ideal, since

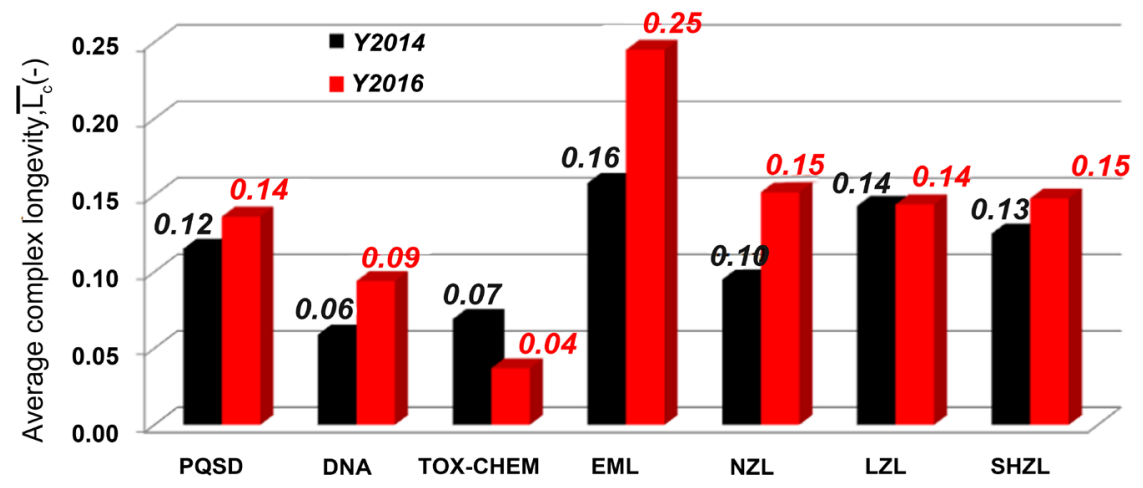

Figure 12. Comparison of the average complex longevity for different laboratories. 
their professionalism and experience is not to be denied. On the other hand, staff with high values of complex longevity (Figure 9) and simple longevity (Figure 6) means that they have been in the FSL for a long time without any experience from outside. The question to be answered by employers is whether all individual staff with $L_{c}$ values higher than 0.3 have good leadership skills or are able to deliver at a high performance as expected. Another element to consider is the level of education or academic development index values in relation to higher $L_{c}$ value, which requires extended research.

\subsection{Analysis of Academic Development Index for FSL Staff}

\subsubsection{Analysis of Academic Development Routes}

Several options for academic development initiatives available for FSL staff were assessed from the data collected from 1980 to Y2016, as shown in Figure 1. Data from 141 staff that completed the academic development checklist was entered into the database. The options or academic development routes were established as shown in Figure 1 (routes A to Q). The data was sorted for each route to establish the number of staff (frequency) which entered into training programs, and those who remained in the same levels until to date. Figure 13 shows the frequency as a percentage of FSL staff for each route.

While most of the routes show none of the staff, most of FSL staff opted for $\mathrm{BSc}$ to MSc, that is, route $\mathrm{C}$. The largest number of staff took routes $\mathrm{K}$ and $\mathrm{D}$, that is, BSc to date, followed by MSc to date. This analysis is useful for human resource professionals in the FSL in advising the staff during making choice before embarking on further studies. In general, compared to results presented in

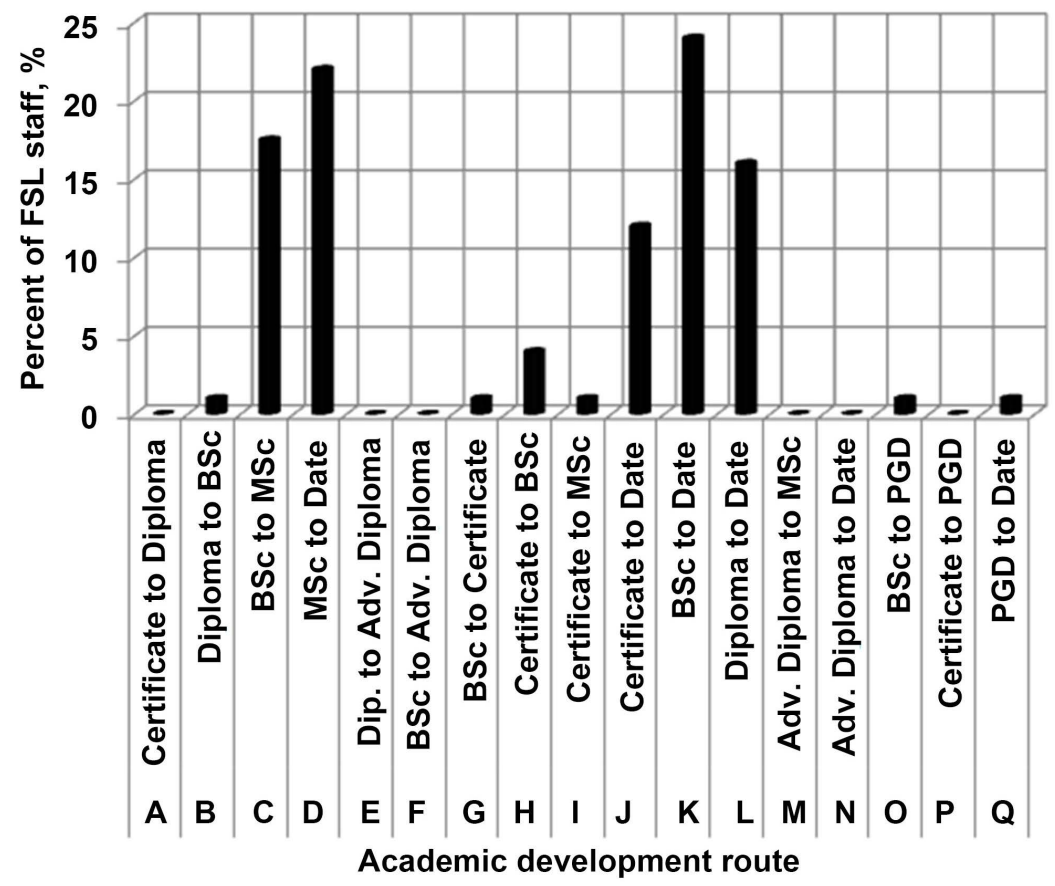

Figure 13. Frequency distribution of the FSL staff following different academic development routes (1980 to 2015). 
Figure 6, few staff had taken initiatives to embark into further studies within the FSL. It was further established that counting the number of attempts for further studies each FSL staff have undertaken or the number routes the individual staff has taken throughout their work-life in FSL, 71.6\%, $24.8 \%$ and $2.8 \%$ of the staff have taken one, two and three routes, respectively. That is at least $72 \%$ of the FSL has got chance to embark on further studies and improve their academic levels. This is commendable for a public institution in striving to remain competitive.

\subsubsection{Individual Staff Academic Development Index for Different Departments}

Figure 14 compares the individual staff academic development index, $A_{d}$, for FSL core cadre. The letters on the horizontal axis in Figure 14 denotes individual staff identification. The values of $A_{d}$ for staff in three technical departments were compared in this study (FSDS, CMD and PQSD). All values of $A_{d}$ varied from 1.0 to $2.2,1.0$ to 1.5 and 1.0 to 2.15 for FSDS, CMD and PQSD, respectively. The maximum values of $A_{d}$ were however, lowest for staff in the CMD.

In Figure 14, the symbols $R_{d}$ denote redundancy in staff allocation (e.g., two staff Band C in PQSD and two staff A and B in FSDS), while $G_{p}$ denotes a gap in staff allocation (e.g., between staff B and C in FSDS, and between staff C and D in PQSD). Thus, to attain a practical balance in terms of $A_{d}$ three staff movement can be suggested, that is, movement $\mathrm{P}$, where staff identified as B is moved from FSDS to CMD; movement $\mathrm{Q}$, where staff identified as B is moved from FSDS to CMD; and finally, movement $\mathrm{R}$, where staff identified as either $\mathrm{E}$ or $\mathrm{F}$ is moved from FSDS to CMD. The movements $\mathrm{P}, \mathrm{Q}$ and $\mathrm{R}$ will allow the CMD to have $A_{d}$ levels comparable to other departments.

Large value of $A_{d}$ observed for FSDS and PQSD signifies that the individual

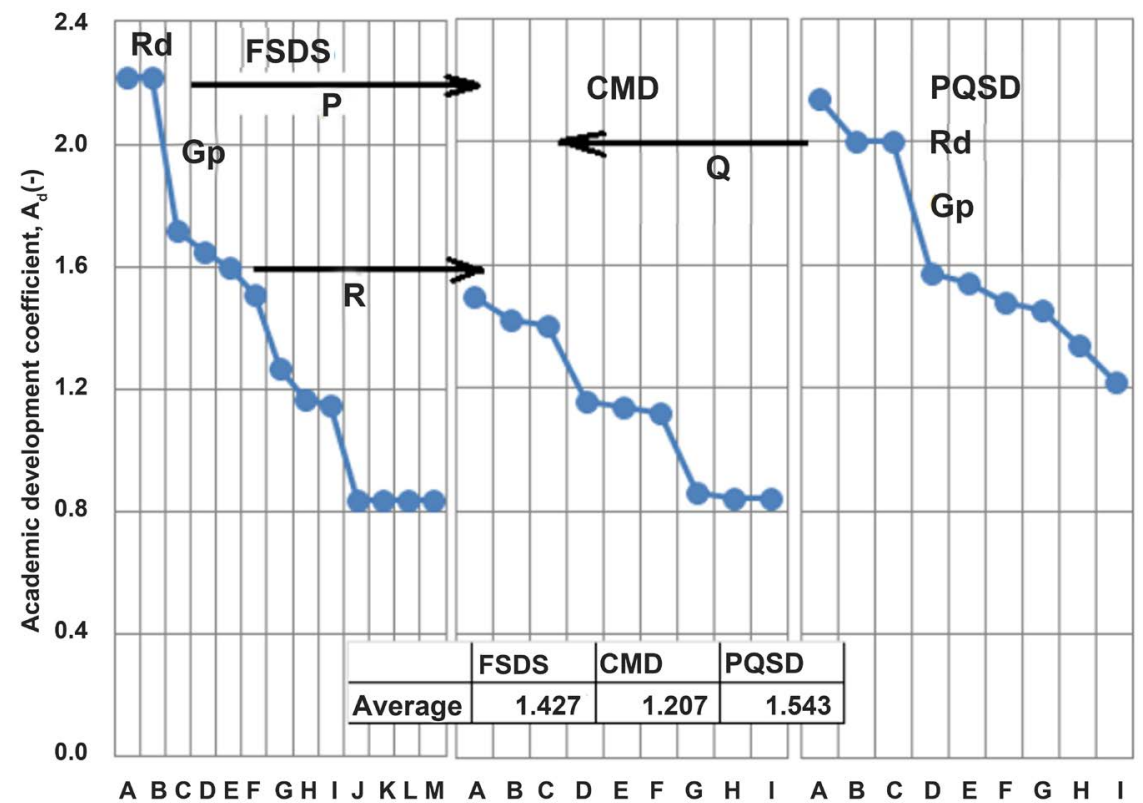

Figure 14. Values of individual staff academic development coefficients, $A_{\phi}$ within FSL departments (Y2016). 
staff attained degrees or certificates in short time intervals while working within the FSL based on Equation (10). On the other hand, a lower value of $A_{d}$ is an indication of staff taking long time to attain next certificates or lack of such efforts during their employment carrier (e.g., CMD). Thus, staff in the CMD attained degrees and certificates in long time intervals than those working in the FSDS and PQSD or they were attending training after employment. This can be attributed to availability of courses and programs related to chemicals and environmental management, compared to forensic science and product quality courses.

While complex longevity signifies the years a given staff has worked with a given degree within the FSL, $A_{d}$ looks at how fast the individual staff acquired new academic certificates while at work (based on reciprocals of the time intervals between certificates). While $L_{c}$ gives score or weight to the academic degrees utilized in the FSL for a given time before attaining another academic level $\left(P_{i} Y_{i}\right), A_{d}$ tracks delays or stagnation time between academic certificates while working in the FSL. Although both are normalized, the two parameters $L_{c}$ and $A_{d}$ are opposite in nature, with low $A_{d}$ indicating longer stagnation between academic certificates and lower $L_{c}$ indicating degrees spent for a short time or lower complex longevity within FSL.

\subsubsection{Classification of Academic Development Index for Different Departments}

Figure 15 shows the frequency distribution of staff falling within three different ranges of $A_{d}$ values A (>2.0), B (1.5 - 2.0) and C $(1.0-1.5)$ for the three technical departments. Results show that the extremely high values of $A_{d}$ (category A) were frequently observed for FSDS (15.4\%) and PQSD (9.1\%) with least number of staff appearing for CMD. For the medium range B, highest frequency of staff was for PQSD followed by FSDS.

On the other hand, in the range $\mathrm{C}$ (which is the unsuitable range as it shows

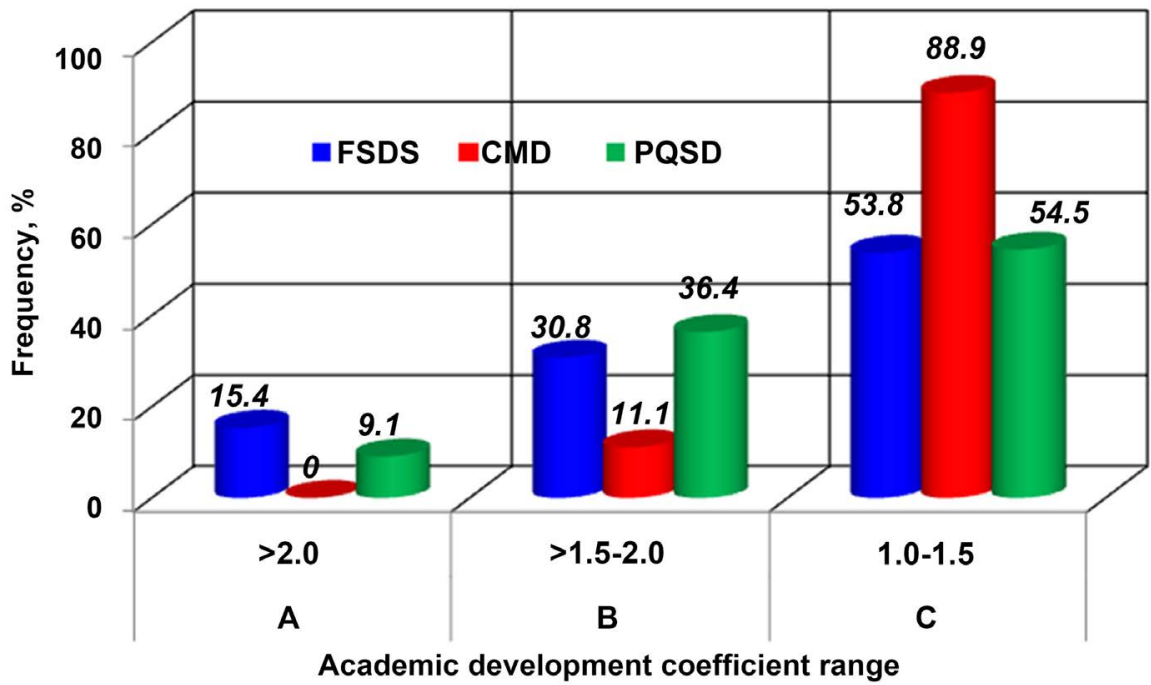

Figure 15. Frequency distribution of FSL staff for three different ranges of academic development index. 
delayed attainment of certificates), highest number of employees in this range was observed for CMD (18.9\%) compared to both FSDS and PQSD. Thus, most advantageous staff were those in FSDS, attributable to arrival of new technology for molecular biology and DNA analysis, which necessitates staff to undergo further studies (BSc to MSc) to cope with the new demands from the Government and the society in general.

\section{Conclusions}

The employment trend analysis shows that diversification of workforce from Y2004 onwards has brought improvements from financial management and procurement management to human resource management leading to higher competitive edge of the FSL. As a result of a training program, the percent of staff with MSc has been increasing from about 3.5\% in Y2004 to 9\% in 2015. The highest total staff simple longevity for different FSL units (for Y2014 and Y2016) was observed in PQSD ( $L_{s}=63$ and 70 years), EML ( $L_{s}=72$ and 65 years) and, LZL ( $L_{s}=71$ and 73 years), respectively. Both $A_{d}$ and $L_{c}$ values were compared for different units and departments including zonal laboratories.

A comparison of individual staff simple longevity, $L_{s}$, for different FSL units showed that PQSD and EML had the highest simple longevity. That is, most experienced employees based on time alone, have been placed in these units. The toxicology/chemistry laboratories have staff with the least $L_{s}$ values. Comparing the values of individual staff complex longevity, $L_{\mathcal{c}}$ for laboratory cadres from different units and zonal laboratories for the Y2016, it is the NZL and EML which showed the highest complex longevity. These are just supporting units of FS.

Both total and average values of $L_{s}, L_{c}$ and $A_{d}$ indicated an imbalance for the distribution of staff in different laboratories, necessitating re-allocation to attain equal distribution of experienced and newly employed staff and hence improve competitiveness of the FSL. This is also observed in total staff complex longevity, for different laboratories, whereby, toxicology/chemistry and DNA laboratories have staff with lower total complex longevity, $L_{c}=0.56$ and 0.34 compared with EML with total complex longevity of 0.95 and 0.98 for the Y2014 and Y2016 respectively.

Comparing individual $A_{d}$ values, FSDS and PQSD shows higher values than $\mathrm{CMD}$, which gives similar conclusion for average values. Analysis of both $L_{c}$ and $A_{d}$ revealed an imbalance in staff placement in the laboratories at headquarters (TOX-CHEM, EML, and PQSD) compared to zonal laboratories, necessitating re-allocation of staff. The overall average $L_{c}$ for all staff increased between Y2014 and Y2016, indicating improvement in staff academic development and longevity. While DNA laboratory requires staff with specialized knowledge and skills, and re-allocation of staff in zonal laboratories has financial implications, a balanced staff distribution based on $L_{c}$ and $A_{d}$ is inevitable. The average values of $L_{s} L_{c}$ and $A_{d}$ are the better parameters for comparing laboratories or units than 
the total values. Thus, the newly developed complex longevity, $L_{c}$ and academic development index, $A_{\phi}$ are important tools for describing the employee development.

\section{Acknowledgements}

The authors are grateful to the GCLA Management for financial support which enabled completion of this study. Special thanks to the Human Resource Officers for organizing the data collection exercise (N.O. Nombo, B. Lankii, G. Kasembe and A. Mapunda).

\section{Conflicts of Interest}

The authors declare no conflicts of interest regarding the publication of this paper.

\section{References}

[1] Garavan, T.N., Morely, M., Gunnigle, P. and Collins, E. (2001) Human Capital Accumulation: the Role of Human Resource Development. Journal of European Industrial Training, 25, 48-68. https://doi.org/10.1108/EUM0000000005437

[2] Hameed, A. and Waheed, A. (2011) Employee Development and Its Effect on Employee Performance: A Conceptual Framework. International Journal of Business and Social Science, 2, 224-229.

[3] Nordhaug, O. (1998) Competencies Specificities in Organizations. International Studies of Management and Organisation, 28, 8-29. https://doi.org/10.1080/00208825.1998.11656725

[4] Iles, P.A., Mabey, C. and Robertson, I.T. (1990) HRM Practices and Employee Commitment: Possibilities, Pitfalls and Paradoxes. British Journal of Management, 1, 147-157. https://doi.org/10.1111/j.1467-8551.1990.tb00003.x

[5] Robertson, M. and O’Malley-Hammersley, G. (2000) Knowledge Management Practices within a Knowledge-Intensive Firm: The Significance of the People Management Dimension. Journal of European Industrial Training, 24, 241-253. https://doi.org/10.1108/03090590010321205

[6] Collis, D.J. and Montgomery, C.A. (1995) Competing on Resources: Strategy in the 1990s. Harvard Business Review, 73, 118-128.

[7] Green, F. (1993) The Determinants of Training of Male and Female Employees in Britain. Oxford Bulletin of Economics and Statistic, 55, 103-122. https://doi.org/10.1111/j.1468-0084.1993.mp55001006.x

[8] Mincer, J. (1997) The Production of Human Capital and the Life Cycle of Earnings: Variations on a Theme. Journal of Labor Economics, 15, 26-47. https://doi.org/10.1086/209855

[9] Bates, T. (1990) Entrepreneur Human Capital Inputs and Small Business Longevity. The Review of Economics and Statistics, 72, 551-559. https://doi.org/10.2307/2109594

[10] Goetz, S.J. and Hu, D. (1996) Economic Growth and Human Capital Accumulation: Simultaneity and Expended Convergence Tests. Economics Letter, 51, 355-362. https://doi.org/10.1016/0165-1765(96)00827-0

[11] Doucouliagos, C. (1997) The Aggregate Demand for Labor in Australia: A Me- 
ta-Analysis. Australian Economic Papers, 36, 224-242. https://doi.org/10.1111/j.1467-8454.1997.tb00847.x

[12] Dooley, E. (2000) Intellectual Capital in the Software Industry: An Empirical Test. PhD Dissertation, College of Business Administration, University of Washington, Tacoma, WA.

[13] Seleim, A., Ashour, A. and Bontis, N. (2007) Human Capital and Organizational Performance: A Study of Egyptian Software Companies. Management Decision, 45, 789-801. https://doi.org/10.1108/00251740710746033

[14] Bontis, N. and Fitzenz, J. (2002) Intellectual Capital ROI: A Current Map to Human Capital Antecedents and Consequences. Journal of Intellectual Capital, 3, 223-247. https://doi.org/10.1108/14691930210435589

[15] Hsu, I.C., Lin, C.Y.Y., Lawler, J.J. and Wu, S.H. (2007) Toward a Model of Organizational Human Capital Development: Preliminary Evidence from Taiwan. Asia Pacific Business Review, 13, 251-275. https://doi.org/10.1080/13602380701233547

[16] Selvarajan, T.T., Ramamoorthy, N., Flood, P.C., Guthrie, J.P., MacCurtain, S. and Liu, W. (2007) The Role of Human Capital Philosophy in Promoting Firm Innovativeness and Performance: Test of a Causal Model. International Journal of Human Resource Management, 18, 1456-1470. https://doi.org/10.1080/09585190701502588

[17] Shrader, R. and Siegal, D.S. (2007) Assessing the Relationship between Human Capital and Firm Performance: Evidence from Technology-Based New Ventures. Entrepreneurship Theory and Practice, 31, 893-908. https://doi.org/10.1111/j.1540-6520.2007.00206.x

[18] Noe, R.A., Hollenbeck, J.R., Gerhart, B. and Wright, P.M. (2003) Human Resource Management: Gaining a Competitive Advantage. 4th Edition, McGraw-Hill, Boston.

[19] Youndt, M.A., Subramaniam, M. and Snell, S.A. (2004) Intellectual Capital Profiles: An Examination of Investments and Returns. Journal of Management Studies, 41, 335-361. https://doi.org/10.1111/j.1467-6486.2004.00435.x

[20] Delaney, J.T. and Huselid, M.A. (1996) The Impact of Human Resource Management Practices on Perceptions of Organizational Performance. Academy of Management Journal, 39, 949-969.

[21] McLean, J. and McManus, J. (2009) Using Workplace Learning as a Lens to Reframe Academic Development. 6th International Researching Work and Learning Conference, Roskilde University, Denmark, 28 June-1 July 2009.

[22] Hodkinson, P. and Hodkinson, H. (2004) The Significance of Individuals' Dispositions in Workplace Learning: A Case Study of Two Teachers. Journal of Education and Work, 17, 167-182. https://doi.org/10.1080/13639080410001677383

[23] Manyele, S.V., Nombo, N.O., Omari, G.C. and Mwaluko, G. (2017) Competitiveness Analysis for Forensic Science Laboratory Using Employee Professional Development Data. Engineering, 9, 1018-1047. https://doi.org/10.4236/eng.2017.912061

[24] Maimunah, I. and Lawrence, A. (2008) Workforce Diversity: A Human Resource Development Perspective towards Organizational Performance. European Journal of Social Sciences, 6, 244-251. 